\title{
Value addition to lignocellulosics and biomass-derived sugars: An insight into solid acid-based catalytic methods
}

\author{
PRASENJIT BHAUMIK, A K DEEPA, TANUSHREE KANE and \\ PARESH LAXMIKANT DHEPE* \\ Catalysis and Inorganic Chemistry Division, CSIR- National Chemical Laboratory, Dr. Homi Bhabha Road, \\ Pune 411 008, India \\ e-mail: pl.dhepe@ncl.res.in
}

MS received 4 July 2013; revised 11 December 2013; accepted 12 December 2013

\begin{abstract}
For the synthesis of important platform chemicals such as sugars (xylose and arabinose) and furans (furfural and 5-hydroxymethylfurfural (HMF)) from carbohydrates (hemicellulose and fructose) solid acid catalysts are employed. Similarly, over solid acid catalysts, conversion of lignin into aromatic monomers is performed. It is observed that in the dehydration of fructose, because of higher hydrothermal stability, silicoaluminophosphate (SAPO) catalysts give better activity (78\% HMF yield) compared with other solid acid catalysts $\left(<63 \% \mathrm{HMF}\right.$ yield) at $175^{\circ} \mathrm{C}$. Particularly, SAPO-44 catalyst can be reused at least 5 times with marginal decrease in the activity. Zeolite, $\mathrm{HUSY}(\mathrm{Si} / \mathrm{Al}=15)$ is active in the conversion of isolated (pure) hemicellulose to produce $41 \% \mathrm{C}_{5}$ sugars in water. The catalyst is also active in the selective conversion of hemicellulose from bagasse to yield $59 \% \mathrm{C}_{5}$ sugars. It is possible to obtain high yields of furfural $(54 \%)$ directly from bagasse if instead of water, water+toluene solvent system is used. Depolymerization of lignin using HUSY catalyst produced aromatic monomers with $60 \%$ yield at $250^{\circ} \mathrm{C}$. A detailed catalyst characterization study is performed to understand the correlation between catalyst activity and morphology. To understand the effect of impurities present in the substrate over solid acid catalysts, metal-exchange study is carried out.
\end{abstract}

Keywords. Aromatic monomers; biomass; furans; hemicellulose; lignin; solid acid catalyst.

\section{Introduction}

A keen interest shown by Government as well as researchers towards the use of abundant, renewable feedstock, biomass for the synthesis of chemicals may take care of most of the issues related to depleting fossil resource. ${ }^{1-6}$ Worldwide production of lignocelluloses is around 1.8 trillion tons ${ }^{7}$ and India alone generates ca. 624 million tons of crop waste annually in the form of lignocellulosics (crop waste). ${ }^{8}$ Major components of crop waste are cellulose $(\beta-1,4-\mathrm{D}$-glucose; 40-50\%), hemicelluloses (co-polymer of $\mathrm{C}_{5}$ and $\mathrm{C}_{6}$ sugars; 25-35\%) and lignin (macromolecular network of phenyl-propane units; 15-20\%). ${ }^{9}$ Robustness in structure and high $\mathrm{O} / \mathrm{C}$ ratio in biomass disapprove its compatibility with the present catalytic system and demands development of modified processes. The most attractive and promising approach is to produce furan derivatives from biomass, for e.g., furfural from hemicelluloses/xylose and 5-hydroxymethylfurfural (HMF) from cellulose/glucose/fructose, because of their importance

\footnotetext{
*For correspondence
}

as platform chemicals. ${ }^{10-12}$ Recently, researchers have are also been engaged in lignin valorization to yield versatile aromatic chemicals that can be used as fuel additives or can find niche applications. ${ }^{13}$

Typically, hemicellulose is hydrolysed to form $\mathrm{C}_{5}$ sugars (xylose+arabinose) and which on further dehydration (loss of water molecules) produce furfural. ${ }^{14}$ Furfural can be further converted into various important chemicals such as furfuryl alcohol, ${ }^{15}$ 2-methylfuran (MF) ${ }^{15}$ 2-methyltetrahydrofuran (MTHF) ${ }^{15}$ linear alkanes, ${ }^{16}$ phenol-formaldehyde resin, ${ }^{17}$ furoic and maleic acid ${ }^{12}$ which for decades have well-known industrial scale processes/applications. Furfural can be produced from xylose or directly from hemicellulose and the available processes are described here.

\subsection{Xylose as substrate}

Literature describes that furfural is mainly produced from xylose (scheme 1) and the traditional processes are based on homogeneous catalysis. Homogeneous acids such as $\mathrm{HCl}, \mathrm{H}_{2} \mathrm{SO}_{4}, \mathrm{HNO}_{3}, \mathrm{CH}_{3} \mathrm{COOH}, \mathrm{H}_{3} \mathrm{PO}_{4}$ and $\mathrm{HCOOH}$ were studied for the conversion of xylose at $135-180^{\circ} \mathrm{C}$ in water to yield furfural. ${ }^{18-20}$ 


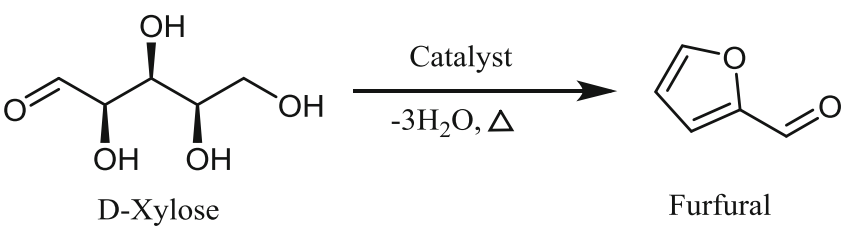

Scheme 1. Production of furfural from xylose.

Due to obvious hazards in handling these acids, solid acid catalysed method has been proposed to provide a cleaner and environment friendly production of furfural. Zeolite, HZSM-5 in water at $200^{\circ} \mathrm{C}$ yields $46 \%$ of furfural from xylose. ${ }^{21}$ Lewis acid type catalyst Sn-beta was also studied with the formation of furfural (14\% yield). ${ }^{22}$ Graphene, graphene oxide, sulphonated graphene and sulphonated graphene oxides at $200^{\circ} \mathrm{C}$ in water produce $51-62 \%$ of furfural from xylose. ${ }^{23}$ Though water is the most preferred solvent, it is observed that reactions carried out only in water accelerate undesired side reactions and lower furfural yield. ${ }^{24}$ In view of this, polar aprotic solvent such as acetonitrile, dimethyl formamide (DMF) and dimethyl sulphoxide (DMSO) were tried. Among studies on polar aprotic solvents, DMSO yields highest amount of furfural (78\%) in presence of Amberlyst-15 at $170^{\circ} \mathrm{C} .{ }^{25-30}$ DMSO minimizes side reactions but at the same time its high boiling point and poor sugar solubility severely affects the process. ${ }^{11}$ To improve the yields, water miscible organic solvent system is also used. $\mathrm{H}_{2} \mathrm{O}$-acetone-DMSO system was studied in presence of $\mathrm{SO}_{4}^{2-} / \mathrm{C}$ catalyst at $230^{\circ} \mathrm{C}$, yielding very less furfural yield $(11.5 \%) .{ }^{31}$ However, $\mathrm{H}_{2} \mathrm{O} / 1$-butanol solvent system improves the yield (44\%) with MCM41 at $170^{\circ} \mathrm{C}^{32}$ Introduction of immiscible biphasic solvent system (water+organic solvent) improves furfural yield since organic solvent extracts furfural from the aqueous layer and thereby diminishes the possibility of undesired reactions. Studies on $\mathrm{H}_{2} \mathrm{O}$ /MIBK (methyl iso-butyl ketone) biphasic system with catalysts such as $\mathrm{HMOR},{ }^{33} \mathrm{HY}^{33}$ and $\mathrm{MCM}-41-\mathrm{SO}_{3} \mathrm{H}^{27}$ yields furfural in the range of $20-51 \%$. Very good extracting ability of toluene for furfural makes it the best solvent for furfural synthesis. ${ }^{34} \mathrm{~A}$ wide range of solid acid catalysts such as $\mathrm{H}$-form of zeolites, ${ }^{28,33,35}$ $\mathrm{H}_{3} \mathrm{PW}_{12} \mathrm{O}_{40} / \mathrm{MCM}-41,{ }^{30} \quad \mathrm{Cs}_{3} \mathrm{PW}_{12} \mathrm{O}_{40} / \mathrm{MCM}-41,{ }^{29}$ HMCM-22, ${ }^{36}$ MCM-41-SO ${ }_{3} \mathrm{H},{ }^{27}$ H-Al-MCM-41, ${ }^{37}$ $\mathrm{SO}_{4}^{2-} / \mathrm{ZrO}_{2}-\mathrm{Al}_{2} \mathrm{O}_{3} / \mathrm{SBA}-15,{ }^{38}$ BEA-TUD-1, ${ }^{36}$ ITQ$2,{ }^{36} \quad \mathrm{SO}_{4}^{2-} / \mathrm{SnO}_{2},{ }^{39} \quad(\mathrm{VO})_{2} \mathrm{P}_{2} \mathrm{O}_{7},{ }^{40} \quad \mathrm{SBA}-15 / \mathrm{SO}_{3} \mathrm{H},{ }^{41}$ Amberlyst-70, ${ }^{42}$ SAPO-11, ${ }^{43}$ Del-Nu-6 ${ }^{37}$ and $\mathrm{H}_{4} \mathrm{TiNbO}_{5}-\mathrm{MgO}^{44}$ were studied in $\mathrm{H}_{2} \mathrm{O}$ /toluene biphasic system. Zeolite, $\mathrm{HMOR}^{35}$ yields highest amount of furfural (98 mole\%) from xylose in plug-flow reactor at $260^{\circ} \mathrm{C}, 55$ bar pressure. For other catalysts, yields remain in the lower range of $31-71 \%$. It is important to note here that though several catalysts show activity in these reactions, their stability in water is questionable. For e.g., ion-exchange resins are mostly unstable in water above $130^{\circ} \mathrm{C}$, and mesoporous silicas tend to undergo structural changes above $150^{\circ} \mathrm{C}$ in water medium. The HPAs are also hydrothermally less stable and show leaching of active species.

The tunable properties of ionic liquids (ILs) also attract researchers. ILs are used as a solvent and also as a catalyst for furfural production. ${ }^{45,46}$ Although, good yields are obtained, various drawbacks such as homogeneous nature of catalyst and difficulties associated with recyclability of ILs indicates that more work should be done in this area.

\subsection{Furfural from hemicellulose (via xylose and arabinose)}

Use of isolated (pure) xylose as a feedstock for the production of furfural is not economical as it is mainly obtained from hemicelluloses after hydrolysis in a separate reactor. Hence, it is desirable to obtain furfural directly from hemicellulose via xylose formation in a one-pot method (scheme 2). Very few reports are available on this reaction using solid acid catalysts. ${ }^{47,48}$ A two-step process is also reported for this reaction, where in the first step (auto-hydrolysis), formation of water soluble oligomers from hemicellulose (xylan) at $160^{\circ} \mathrm{C}$ is carried out; and then in the second step ionexchange resin (Amberlyst-15) is used to produce $\mathrm{C}_{5}$ sugars (90\%). ${ }^{49,50}$ Arabinogalactan (hemicellulose) can produce arabinose in high yield $(95 \%)$ with the help of Smopex-101 catalyst. ${ }^{51}$

HMF is a multifunctional molecule as it contains aromatic aldehyde and aromatic alcohol functional groups and is made up of a furan ring system. By converting

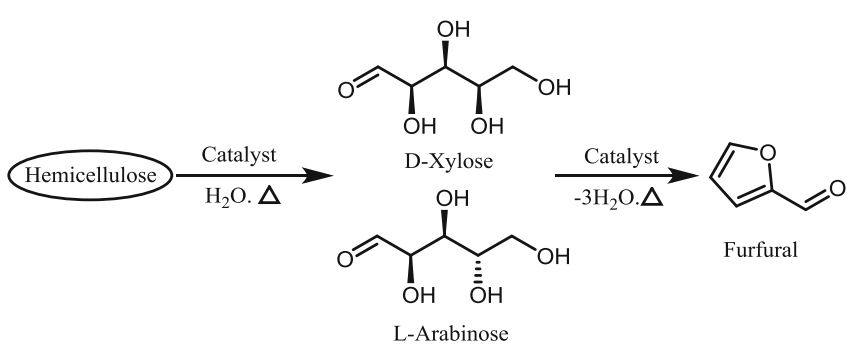

Scheme 2. Production of furfural from hemicelluloses as substrate. 


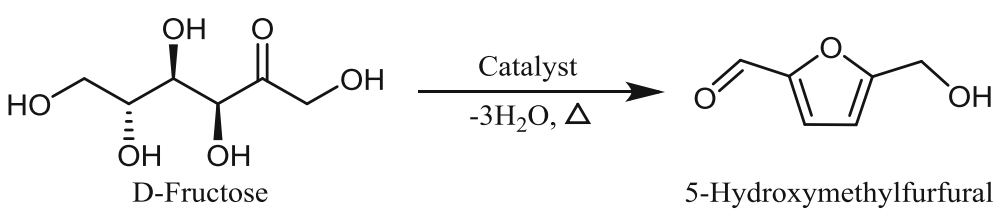

Scheme 3. Production of 5-hydroxymethylfurfural (HMF) from fructose.

these functional groups, it is possible to synthesize various products and hence HMF is described as a 'sleeping giant'. $52,53 \mathrm{HMF}$ is used for the production of 2, 5-dihydroxymethylfuran (DHMF), ${ }^{54} 2,5$ dimethylfuran (DMF) ${ }^{54}$ 2, 5-dimethyltetrahydrofuran (DMTHF), ${ }^{55}$ 2, 5-diformylfuran (DFF), ${ }^{56} \quad$ 2, 5furandicarboxylic acid (FDCA), ${ }^{57}$ formic and levulinic acid ${ }^{58}$ and liquid alkanes. ${ }^{59}$ HMF is mainly produced from fructose (scheme 3), though other substrates such as glucose, inulin, maltose, cellobiose, cellulose, starch, etc., can also be used.

\subsection{Fructose as feedstock}

A study on water-only system in presence of $\mathrm{TiO}_{2}$, $\mathrm{ZrO}_{2}$ and $\mathrm{TiO}_{2}$ nanoparticles showed very low yields of HMF (30-38\%) from fructose since water favours side reactions. ${ }^{60,61}$ To minimize the formation of unwanted side products, use of organic solvent was initiated. Use of DMSO solvent can improve HMF yield to $54 \%$ compared to water (34\% yield) in presence of $\mathrm{TiO}_{2}$ nanoparticles. ${ }^{61}$ Amberlyst- 15 in presence of DMSO showed the best activity (100\% HMF yield) while Nafion-H catalyst has comparatively poor activity $(75 \%){ }^{62}$ It appears that DMSO is the best solvent but as mentioned earlier due to its drawbacks it cannot be probed further. Other organic solvents such as DMF (73\%), tetrahydrofuran (THF; 45\%) and isopropanol $(\sim 45 \%)$ yields HMF in lower concentrations in presence of Amberlyst-15. ${ }^{63-65}$ Incorporation of biphasic solvent system improves the HMF yield due to its preferential extraction in organic solvent and thereby protects it from further degradation or condensation reactions. In $\mathrm{H}_{2} \mathrm{O}$ /MIBK system, HMOR showed the best activity (74\% HMF yield) among other zeolites such as HZSM-5 and $\mathrm{H} \beta{ }^{66,67} \mathrm{Cs}_{2.5} \mathrm{H}_{0.5} \mathrm{PW}_{12} \mathrm{O}_{40}$ and $\mathrm{Ag}_{3} \mathrm{PW}_{12} \mathrm{O}_{40}$ were also examined in $\mathrm{H}_{2} \mathrm{O} / \mathrm{MIBK}$ system to yield $74-77 \%$ of $\mathrm{HMF}^{68,69}$ Study on $\mathrm{H}_{2} \mathrm{O} / 2$ butanol system showed that hydrated Ta-oxide (Tap) has better activity than $\mathrm{Nb}_{2} \mathrm{O}_{5}$ and $\mathrm{Ta}_{2} \mathrm{O}_{5} \cdot{ }^{70}$ Mixed organic solvent system such as acetone/DMSO were studied with ion-exchange resin giving $89 \%$ HMF yield. ${ }^{71}$

\subsection{Other monomers, dimers and polymers as feedstock}

The reports mentioned here depict that dehydration of fructose to HMF is possible; however, in terms of availability of feedstock, this process is not proficient. Considering this, to obtain HMF, use of inexpensive and abundant feedstock glucose is desirable. Glucose to HMF reaction is a two-step process, where the first step involves isomerization reaction to form fructose from glucose (base-catalysed) and second step involves dehydration of fructose to HMF (acid-catalysed). Many catalytic systems which favour fructose conversion to HMF show disappointing results in the glucose to HMF reaction since glucose forms a stable pyranose ring in water and first needs to be converted to fructose. So, the lower fraction of open chain molecules available in solution gave lower rate of enolization, which is the rate determining step for HMF formation from glucose. Realizing that formation of HMF from glucose is a twostep process carried out using catalysts having varying properties (basic and acidic), it is very difficult to carry out this scheme in one pot. Combination of base and acid catalysts such as HT and Amberlyst-15 is used in DMF solvent for achieving maximum of $42 \% \mathrm{HMF}$ yield at $100^{\circ} \mathrm{C}$ in $9 \mathrm{~h}^{63}$ This report showed three-time recyclability of HT/Amberlyst- 15 at $100^{\circ} \mathrm{C}, 3 \mathrm{~h}$ with ca. $25 \% \mathrm{HMF}$ yield. It was proposed that presence of Lewis acid sites in Sn-beta catalyst can promote isomerization reaction of glucose to fructose. ${ }^{72,73}$ Further addition of $\mathrm{HCl}$ to the reaction with Sn-beta catalyst gave 57\% HMF yield. ${ }^{72,73}$ Recyclability of Sn-beta catalyst was shown for isomerization reaction with $30 \%$ fructose yield over four runs. ${ }^{72} \mathrm{TiO}_{2}, \mathrm{ZrO}_{2}$ and $\mathrm{TiO}_{2}$ nanoparticles were also studied to yield lower amount of HMF (10-29\%). ${ }^{60,61}$ $\mathrm{Sn}-\mathrm{W}$ oxide catalyst was evaluated in this reaction and it yielded $48 \%$ of HMF from glucose. ${ }^{74}$ HT/Amberlyst15 was tried for the conversion of sucrose and cellobiose in DMF solvent to yield 54\% and 34\% of HMF, respectively. ${ }^{63} \mathrm{Sn}-\mathrm{W}$ oxide was also efficient in converting cellobiose and starch to yield $\sim 40 \% \mathrm{HMF}^{74} \mathrm{~A}$ major drawback in most of these reports is that catalyst morphology and recyclability is not mentioned. 


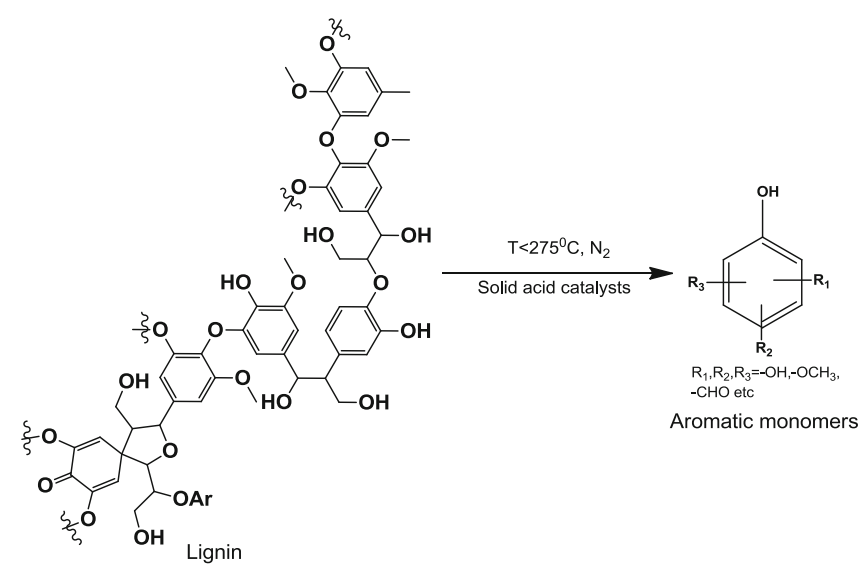

Scheme 4. Lignin depolymerization using solid acid catalysts.

Valorization of lignin produces a variety of chemicals such as aromatic monomers and gases which have diverse industrial applications (scheme 4). Conversion of lignin into value-added products using competent and green process is required to achieve favourable economics for the cellulose to bioethanol process. ${ }^{75}$ Lignin is made up of a complex three-dimensional amorphous aromatic biopolymer consisting of main building blocks of $p$-coumaryl alcohol, coniferyl alcohol and sinapyl alcohol. In the literature, several methods of valorizing lignin are mentioned. A well-known base-catalysed depolymerization (BCD) method $^{76,77}$ uses homogeneous mineral bases $(\mathrm{NaOH} / \mathrm{KOH})$ for the conversion of lignin into aromatic monomers above $260^{\circ} \mathrm{C}$. Use of mineral bases to yield either aromatic monomers or gases has been claimed by others. ${ }^{78,79}$
However, soluble base method generates neutralization waste, corrosion to reactor and thus is not ecofriendly. Efforts have been diverted towards the use of supported metal catalysts ( $\mathrm{Pt}, \mathrm{Ru}, \mathrm{Pd}, \mathrm{Ni}, \mathrm{Co}-\mathrm{Mo}, \mathrm{Ni}-$ Mo supported on $\mathrm{C}, \mathrm{Al}_{2} \mathrm{O}_{3}, \mathrm{SiO}_{2}-\mathrm{Al}_{2} \mathrm{O}_{3}$ or zeolites) under hydrogen atmosphere to convert lignin into aromatic monomers and gases. ${ }^{80-84}$ Although good results are achieved, use of precious metals and hydrogen make these methods economically unviable. Reports claim that pyrolysis of lignin produces bio-oils in the absence of oxygen at higher temperatures $\left(>250^{\circ} \mathrm{C}\right){ }^{85}$ Lignin conversion under supercritical water conditions $\left(>275^{\circ} \mathrm{C}\right)$ is reported to yield various gases depending upon the reaction conditions employed. ${ }^{86,87}$ Catalytic cracking of bio-oils is also known over HZSM-5 $\geq 340^{\circ} \mathrm{C}$ to form aromatic hydrocarbons. ${ }^{88}$ Pre-treatment of lignin with homogeneous reagents $\mathrm{NaOH}, \mathrm{H}_{2} \mathrm{O}_{2}$ and $\mathrm{Ca}(\mathrm{OH})_{2}$ followed by pyrolysis using heterogeneous catalysts to yield ca. $90 \%$ yield however defeats the purpose of using heterogeneous catalysts. ${ }^{89}$ Yet, majority of studies are done using lignin model compounds (dimers and trimers) instead of real lignin as a substrate. This particularly, hampers in developing a catalytic systems as actual substrates contain several impurities and much more complex structures.

This manuscript mainly describes the recent developments happened in our group related to the production of sugars and furfural from hemicellulose, HMF from fructose and aromatic monomers from lignin with various solid acid catalysts. Physico-chemical characteristics of heterogeneous catalysts used in these studies are mentioned in table 1 .

Table 1. Physico-chemical properties of catalysts.

\begin{tabular}{lcc}
\hline Catalyst & Surface area $\left(\mathrm{m}^{2} \mathrm{~g}^{-1}\right)^{\#}$ & Total acid amount $\left(\mathrm{mmolg}^{-1}\right)^{*}$ \\
\hline $\mathrm{HUSY}(\mathrm{Si} / \mathrm{Al}=15)$ & 873 & 0.55 \\
$\mathrm{HMOR}(\mathrm{Si} / \mathrm{Al}=10)$ & 528 & 1.20 \\
$\mathrm{H} \beta(\mathrm{Si} / \mathrm{Al}=19)$ & 761 & 0.91 \\
$\mathrm{HZSM}-5(\mathrm{Si} / \mathrm{Al}=11.5)$ & 405 & 0.98 \\
$\mathrm{~K} 10$ & 246 & 0.42 \\
$\mathrm{Al}-\mathrm{MCM}-41(\mathrm{Si} / \mathrm{Al}=50)$ & 980 & 0.14 \\
$\mathrm{Al}-\mathrm{SBA}-15(\mathrm{Si} / \mathrm{Al}=100)$ & 1011 & 0.08 \\
$\gamma-\mathrm{Al}_{2} \mathrm{O}_{3}$ & 225 & 0.40 \\
$\mathrm{Nb}_{2} \mathrm{O}_{5}$ & 115 & 0.30 \\
$\mathrm{SiO}_{2}-\mathrm{Al}_{2} \mathrm{O}_{3}(\mathrm{Si} / \mathrm{Al}=5.8)$ & 532 & 0.63 \\
$\mathrm{SAPO}_{4}$ & 369 & 1.20 \\
$\mathrm{SAPO}^{-5}$ & 309 & 0.80 \\
\hline
\end{tabular}

\# $\mathrm{N}_{2}$-sorption analysis; $* \mathrm{NH}_{3}$-TPD analysis 


\section{Experimental}

\subsection{Materials}

Zeolite, HMOR ( $\mathrm{Si} / \mathrm{Al}=10), \mathrm{H} \beta$ ( $\mathrm{Si} / \mathrm{Al}=19), \mathrm{HUSY}$ $(\mathrm{Si} / \mathrm{Al}=15)$ and HZSM-5 $(\mathrm{Si} / \mathrm{Al}=11.5)$ were obtained from Zeolyst International. Prior to use, zeolites were calcined at $550^{\circ} \mathrm{C}$ for $16 \mathrm{~h}$ in air flow. Pseudoboehmite (Marathwada Chemical Industries Pvt. Ltd., grade: MCI-1524, 65-78\% $\mathrm{Al}_{2} \mathrm{O}_{3}$ ), fumed silica (Aldrich), $\gamma$ alumina (Aldrich), silica-alumina (Aldrich), K10 clay (Aldrich), niobium pentoxide (Spectrochem, 99.95\%), orthophosphoric acid (Fisher Scientific, 85\%), cyclohexylamine (Spectrochem, 99\%), hemicellulose/xylan (softwood; xylose $\geq 70 \%$, glucose $15 \%$, arabinose $10 \%$ ) (Aldrich), dealkaline lignin (Aldrich), xylose (LOBA, 99.5\%), arabinose (s. d. fine, 100\%), glucose (s. d. fine, 100\%), furfural (LOBA, 98\%), HMF (Aldrich, 99\%), sodium chloride (LOBA, 99.5\%), potassium chloride (LOBA, 99.8\%), triethyl amine (LOBA, 99\%), toluene (LOBA, 99.5\%), p-xylene (LOBA, 98.5\%), MIBK (LOBA, 99\%), THF (LOBA, 99.5\%) and methanol (LOBA, 99.8\%) were purchased and used as received.

\subsection{Synthesis of catalysts}

Synthesis of crystalline silicoaluminophosphate materials was carried out according to a published report. ${ }^{90,91}$ Pseudoboehmite, fumed silica and orthophosphoric acid were used as source of $\mathrm{Al}_{2} \mathrm{O}_{3}, \mathrm{SiO}_{2}$ and $\mathrm{P}_{2} \mathrm{O}_{5}$, respectively during synthesis.

A molar gel composition of 1.0 CHA: $1.0 \mathrm{Al}_{2} \mathrm{O}_{3}: 1.0$ $\mathrm{SiO}_{2}: 1.0 \quad \mathrm{P}_{2} \mathrm{O}_{5}: 60.0 \quad \mathrm{H}_{2} \mathrm{O}$ was used in synthesis of SAPO-44 material. ${ }^{90}$ Typically, 4.60 g pseudoboehmite was added slowly (within $2 \mathrm{~h}$ ) to the diluted phosphoric acid solution (7.69 $\mathrm{g} \mathrm{H}_{3} \mathrm{PO}_{4}+12.50 \mathrm{~g}$ water) to form gel A. Gel B was prepared by mixing of $2.05 \mathrm{~g}$ of fumed silica in $23.50 \mathrm{~g}$ water followed by addition of 3.33 g CHA (cyclohexylamine). Now, gel B was added to gel A and stirred for $6 \mathrm{~h}$. The homogeneous solution was transferred to Teflon lined steel autoclave and aged (crystallization) for $176 \mathrm{~h}$ at $200^{\circ} \mathrm{C}$. Solid materials were filtered, washed with water, dried and calcined at $550^{\circ} \mathrm{C}$ for $6 \mathrm{~h}$ in air.

A molar gel composition of 1.0 TEA:1.0 $\mathrm{Al}_{2} \mathrm{O}_{3}: 0.4$ $\mathrm{SiO}_{2}: 1.0 \mathrm{P}_{2} \mathrm{O}_{5}: 50.0 \mathrm{H}_{2} \mathrm{O}$ was used to synthesize SAPO5 material. ${ }^{91}$ Typically, $1.00 \mathrm{~g}$ of pseudoboehmite was added (within $2 \mathrm{~h}$ ) to diluted phosphoric acid (1.58 g $\mathrm{H}_{3} \mathrm{PO}_{4}+5.95 \mathrm{~g}$ water) to prepare gel A. $0.16 \mathrm{~g}$ fumed silica was mixed thoroughly with $0.69 \mathrm{~g}$ TEA (triethylamine) to get gel B. Both the gels were mixed together and stirred for $3 \mathrm{~h}$ at RT. Obtained solution was aged in an autoclave with teflon liner for $4 \mathrm{~h}$ at $200^{\circ} \mathrm{C}$. Solid materials were filtered, washed with water, dried and calcined at $550^{\circ} \mathrm{C}$ for $6 \mathrm{~h}$ in air.

\subsection{Catalytic reactions}

Furfural formation reactions were carried out with either hemicellulose or bagasse as a substrate. In a typical reaction, $0.6 \mathrm{~g}$ substrate and $0.3 \mathrm{~g}$ catalyst were added to $60 \mathrm{~mL}$ water or water+organic solvent $=30$ $+30 \mathrm{~mL}$ in a Parr autoclave. Autoclave was flushed twice with $\mathrm{N}_{2}$ and finally 50 bar $\mathrm{N}_{2}$ was charged at RT and heated to desired temperature for definite time. Intermediately, samples were withdrawn to monitor the progress of reaction. After reaction, autoclave was cooled to room temperature; catalyst was separated from reaction mixture by centrifugation.

In fructose dehydration reaction, $0.5 \mathrm{~g}$ of fructose, $0.143 \mathrm{~g}$ catalyst were mixed with water+organic solvent $=5 \mathrm{~mL}+25 \mathrm{~mL}$ or $30 \mathrm{~mL}$ water in Parr autoclave and heated at desired temperature under stirring. At the end of reaction, reactor was cooled to room temperature and catalyst was separated from reaction mixture by centrifugation and aqueous and organic layers were separated from each other.

In lignin valorisation reaction, $0.5 \mathrm{~g}$ of dealkaline lignin and $0.5 \mathrm{~g}$ catalyst were mixed with water+methanol $=5 \mathrm{~mL}+25 \mathrm{~mL}$ in Parr reactor and filled with 7 bar $\mathrm{N}_{2}$ at RT. Reactor was heated up to $250^{\circ} \mathrm{C}$ for $0.5 \mathrm{~h}$. At the end of reaction, reactor was cooled to room temperature and catalyst was separated from reaction mixture by centrifugation.

In metal exchange study, different concentrations (20 or $240 \mathrm{ppm}$ ) of metal chloride salt solution were added to catalyst and stirred for $24 \mathrm{~h}$ at $60^{\circ} \mathrm{C}$. Then catalysts were separated through centrifugation and washed with water carefully and dried (oven at $60^{\circ} \mathrm{C}, 16 \mathrm{~h}$; vacuum at $150^{\circ} \mathrm{C}, 16 \mathrm{~h}$ ).

\subsection{Analysis of reaction mixture}

For hemicellulose and fructose reaction, quantification of aqueous layer components was carried out with HPLC, equipped with $\mathrm{Pb}^{2+}$ column $(300 \mathrm{~mm} \times$ $\left.7.8 \mathrm{~mm}, 80^{\circ} \mathrm{C}\right)$, RI detector $\left(40^{\circ} \mathrm{C}\right)$ and Millipore water as mobile phase with $0.6 \mathrm{~mL}$ flow rate. Organic layer components were quantified on a Varian gas chromatograph, equipped with HP-5 column $(50 \mathrm{~m} \times 0.22 \mu \mathrm{m}$ ID) and flame ionization detector (FID).

Lignin reaction mixture is analysed using Varian 3800 model GC equipped with FID and CPSIL 8CB capillary column $(30 \mathrm{~m} \times 0.25 \mathrm{~mm})$. The molecular weight of the products was analysed using Vairan 3800 
GC-MS (Saturn 2000MS) with VF-5 capillary column 2.5 Conversion and yield calculations

$(50 \mathrm{~m} \times 0.25 \mathrm{~mm})$.

Conversion $($ fructose $)=\{[$ Initial fructose - unreacted fructose $($ HPLC) $] /$ Initial fructose $\} \times 100 \%$

Conversion (hemicellulose $)=\{[$ Initial hemicellulose - unreacted hemicellulose (solid recovery basis) $] /$

Initial hemicellulose $\} \times 100 \%$

Yield $=\{$ Weight (from HPLC and GC) $/$ Theoretical weight $\} \times 100 \%$

\subsection{Recycle study}

Catalyst recycle study was carried out with the spent catalyst after calcination at $550^{\circ} \mathrm{C}$ for $12 \mathrm{~h}$ in air.

\section{Results and discussion}

\subsection{Synthesis of furfural}

It is shown that the solid acid catalysts could convert hemicellulose (xylan) to either $\mathrm{C}_{5}$ sugars (xylose, arabinose) and/or furfural depending upon the solvent system used in the reaction. Figure 1 summarizes the results for the catalytic activity observed in aqueous medium for the conversion of isolated xylan to $\mathrm{C}_{5}$ sugars (as major) and furfural (as minor) at $170^{\circ} \mathrm{C}$ using solid acid catalysts. Detail studies on reaction parameters were conducted to find the optimum reaction conditions. Among all the catalysts studied, HUSY (Si/Al $=15$ ) zeolite showed the best activity; ( $41 \%$ yield of xylose+arabinose and $12 \%$ yield of furfural). On the other hand, yields of $\mathrm{C}_{5}$ sugars were less with other

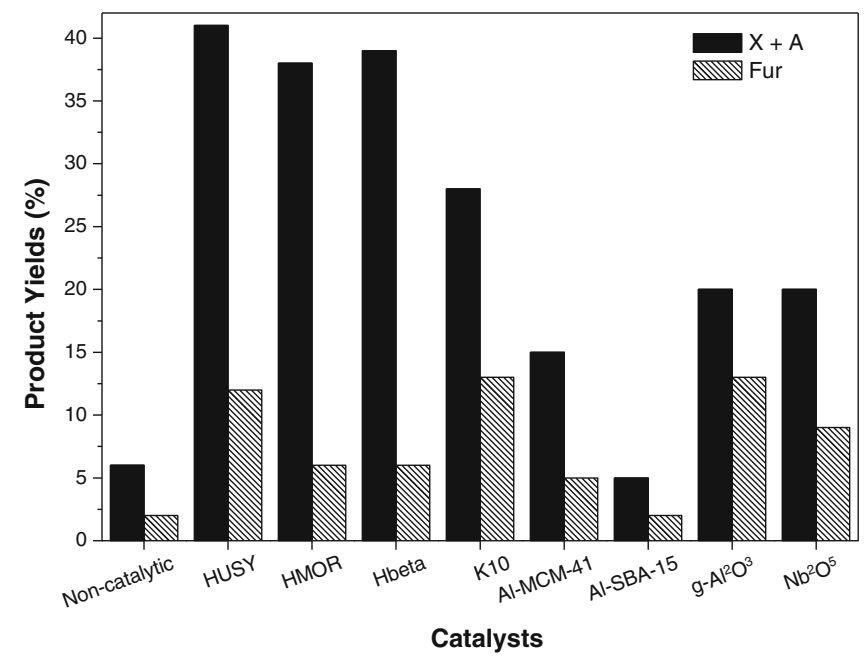

Figure 1. Conversion of hemicellulose to xylose+arabinose $(\mathrm{X}+\mathrm{A})$ and furfural (Fur) using solid acid catalysts. Reaction condition: hemicellulose $(0.6 \mathrm{~g})$, catalyst $(0.3 \mathrm{~g})$, water $(60 \mathrm{~mL}), 50$ bar $\mathrm{N}_{2}$ initial pressure at $\mathrm{RT}, 170^{\circ} \mathrm{C}, 3 \mathrm{~h}$. solid acid catalysts such as $\mathrm{HMOR}(\mathrm{Si} / \mathrm{Al}=10), \mathrm{H} \beta$ $(\mathrm{Si} / \mathrm{Al}=19), \mathrm{K} 10, \mathrm{Al}-\mathrm{MCM}-41(\mathrm{Si} / \mathrm{Al}=50), \mathrm{Al}-\mathrm{SBA}-$ $15(\mathrm{Si} / \mathrm{Al}=100), \gamma-\mathrm{Al}_{2} \mathrm{O}_{3}$ and $\mathrm{Nb}_{2} \mathrm{O}_{5}$. Non-catalytic reaction under similar reaction condition showed only $5 \% \mathrm{C}_{5}$ sugars yield which clarified the effect of catalyst in this reaction. LC-MS technique proved the stepwise formation of polymer (xylan) $\rightarrow$ pentamer $\rightarrow$ tetramer $\rightarrow$ trimer $\rightarrow$ oligomer $\rightarrow$ monomer $\left(\mathrm{C}_{5}\right.$ sugars, xylose and arabinose) $\rightarrow$ furfural. It was shown that HUSY catalyst can be recycled up to 5th run with almost similar activity. ${ }^{47}$

Same strategy was applied to the unpurified hemicellulose (i.e., without separation of cellulose, hemicellulose and lignin from lignocellulose), obtained from bagasse as it is the real crop waste. Bagasse used in this study contains ca. $43 \%$ cellulose, ca. $30 \%$ hemicellulose, ca. $20 \%$ lignin and ca. $7 \%$ extractive+ash. When solid acid catalysts were used in the same S/C ratio of 2 as in previous study, the reaction time gets shorter to $1 \mathrm{~h}$ at $170^{\circ} \mathrm{C}$ to yield maximum amount of xylose+arabinose (figure 2). ${ }^{48}$ With increasing reaction time, decrease in monomer yield was observed. This

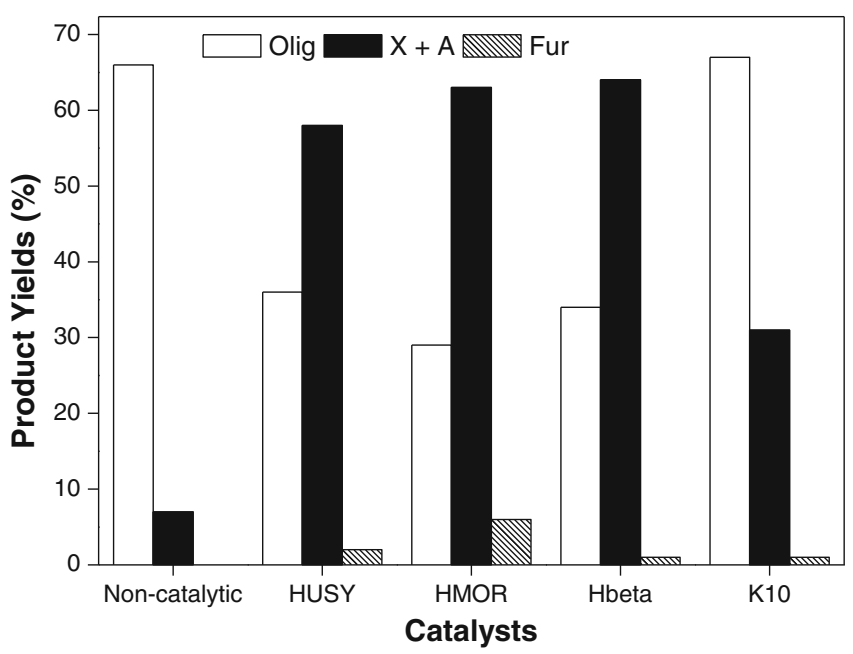

Figure 2. Conversion of bagasse hemicellulose to oligomers (Olig), xylose+arabinose (X+A) and furfural (Fur) using solid acid catalysts. Reaction condition: bagasse $(0.6 \mathrm{~g})$, catalyst $(0.3 \mathrm{~g})$, water $(60 \mathrm{~mL}), 50$ bar initial $\mathrm{N}_{2}$ at RT, $170^{\circ} \mathrm{C}, 1 \mathrm{~h}$. 
could be compensated to form furfural. Zeolite HUSY $(\mathrm{Si} / \mathrm{Al}=15), \mathrm{HMOR}(\mathrm{Si} / \mathrm{Al}=10)$ and $\mathrm{H} \beta(\mathrm{Si} / \mathrm{Al}=19)$ were evaluated under reaction condition and showed almost similar yield of $\mathrm{C}_{5}$ sugars $(60 \pm 4 \%)$ from bagasse, whereas $\mathrm{K} 10$ clay gave $31 \%$ yield for $\mathrm{C}_{5}$ sugars. In case of zeolite, almost 29-36\% oligomers and $3 \%$ furfural were obtained in addition to sugars which allow a total mass balance of $98 \pm 7 \%$ (considering ca. $30 \%$ of hemicellulose present in bagasse). Under similar condition, non-catalytic results showed oligomer as a major product $(65 \%$ yield) with minor amount of $\mathrm{C}_{5}$ sugars (7\%) formation. Non-catalytic conversion of bagasse to oligomer occurs due to thermal hydrolysis and generation of acidic species $\left(\mathrm{H}_{3} \mathrm{O}^{+}\right)$from water at $170^{\circ} \mathrm{C}$. Formation of acidic species can be attributed to change in $p K_{\mathrm{w}}$ value of water from 13.99 to 11.64 when the temperature was increased from $25^{\circ} \mathrm{C}$ to $150^{\circ} \mathrm{C} .{ }^{92} \mathrm{It}$ is important to know whether selectively hemicellulose (part of bagasse) was converted to yield oligomers, $\mathrm{C}_{5}$ sugars and furfural or that the other components (cellulose, lignin) are also undergoing any conversions. To resolve this, reactions were carried out with purified (isolated) cellulose and lignin under similar reaction conditions. The analysis of reaction mixture by GC and HPLC did not show any products formed from these substrates, which confirmed that selectively hemicellulose from bagasse was converted to yield high amount of products.

Since it has been reported that biphasic reaction system improves furfural yield, in our study, we used three different biphasic solvent systems in presence of HUSY as a catalyst for bagasse conversion. ${ }^{48}$ An improved yield of $54 \%$ for furfural was possible by using $\mathrm{H}_{2} \mathrm{O} /$ toluene $(1: 1 \mathrm{v} / \mathrm{v})$ biphasic system at $170^{\circ} \mathrm{C}$, $6 \mathrm{~h}$ in contrast to aqueous-only system; $30 \%$ furfural yield. Also, $\mathrm{H}_{2} \mathrm{O} /$ toluene system produced $23 \%$ oligomer and $18 \% \mathrm{C}_{5}$ sugars along with furfural with a total carbon balance of $95 \%$ based on GC and HPLC analysis. With other biphasic solvent system such as $\mathrm{H}_{2} \mathrm{O} / \mathrm{MIBK}$ and $\mathrm{H}_{2} \mathrm{O} / p$-xylene, improvement in the yield of furfural $(55 \pm 1 \%)$ compared to water-only system was seen. It was observed that higher mass balance can be possible in biphasic system $(95 \pm 1 \%)$ compared to water-only system (79\%). Recycle study was carried out with the recovered catalyst after calcining the catalyst at $550^{\circ} \mathrm{C}$ for $12 \mathrm{~h}$. A decrease in the activity (45\% furfural yield) was observed in the recycle run of a catalyst. This is due to the deposition of carbon or poisoning of active sites on the catalyst during first catalytic run. Further, it was seen that catalyst undergoes morphological changes which was confirmed through various physico-chemical characterizations of catalyst such as XRD, SEM, ICP-OES, solid state NMR, $\mathrm{N}_{2}$-sorption study and $\mathrm{NH}_{3}$-TPD. ${ }^{48}$ For the simplicity of the discussion, we present here, catalyst characterization for HUSY $(\mathrm{Si} / \mathrm{Al}=15)$ catalyst. XRD pattern for spent HUSY showed peaks at similar positions as observed in the fresh catalyst; however, with $30 \%$ decrease in the intensity (figure 3). SEM images confirmed the change in sharp-edge cubic morphology of fresh HUSY to round-edge spherical morphology in spent catalyst. Presence of $\mathrm{Na}$ and $\mathrm{K}$ in the spent HUSY catalyst was proved by ICP-OES study. In the fresh HUSY catalyst, we observed $0.017 \mathrm{mmolg}^{-1}$ of $\mathrm{Na}$; however, on spent catalyst $0.139 \mathrm{mmolg}^{-1}$ of $\mathrm{Na}$ and $0.138 \mathrm{mmolg}^{-1}$ of $\mathrm{K}$ was found. This indicates that source of $\mathrm{Na}$ and $\mathrm{K}$ is the substrate which is obvious since plants require nutrients for their growth and also during the isolation of hemicelluloses from lignocellulosics, $\mathrm{NaOH}$ and $\mathrm{Na}_{2} \mathrm{~S}$ are used (Kraft process). From the ICP analysis of reaction solution, we conclude that $\mathrm{Al}$ is not leached out. Comparison of ${ }^{27} \mathrm{Al}-\mathrm{NMR}$ spectra between fresh and spent HUSY showed decrease in $\mathrm{Al}^{\mathrm{IV}}$ species in spent catalyst wherein intensity of $\mathrm{Al}^{\mathrm{VI}}$ species remained same in both. The decrease in $\mathrm{Al}^{\mathrm{IV}}$ species may be attributed to the formation of NMR invisible species in the spent HUSY. Change in intensity of $\mathrm{Q}^{1}, \mathrm{Q}^{2}, \mathrm{Q}^{3}$ and $\mathrm{Q}^{4}$ species in spent HUSY was observed in ${ }^{29} \mathrm{Si}-\mathrm{NMR}$ spectra. Increase in $\mathrm{Q}^{4}$ [Si(0Al)] species intensity in spent HUSY indicates leaching of Al from the catalyst leading to deactivation. Further, catalyst morphology change was confirmed through $\mathrm{N}_{2}-$ sorption and $\mathrm{NH}_{3}$-TPD studies which showed decrease in surface area from 873 to $704 \mathrm{~m}^{2} \mathrm{~g}^{-1}$, pore volume from 0.45 to $0.38 \mathrm{cc} / \mathrm{g}$ and total acid amount from 0.55 to $0.21 \mathrm{mmolg}^{-1}$. A similar phenomenon of change in the properties is observed with other zeolite catalysts. Hence, it is essential to develop stable and reusable catalysts.

\subsection{HMF production}

As mentioned earlier, HMF has a hidden potential to secure the demand of various chemicals and fuel. It can be synthesized from different substrates such as fructose,${ }^{66,67}$ glucose,${ }^{63}$ starch, ${ }^{46}$ cellulose ${ }^{46}$ and inulin ${ }^{52}$ by the application of homogeneous and heterogeneous catalytic systems. Earlier studies show that in watermediated sugar chemistry with use of high temperature and pressure, changes in the morphology of structured catalysts are possible. ${ }^{47,48}$ Considering this hydrothermally stable $\left(600^{\circ} \mathrm{C}\right.$ under $20 \%$ steam $)$ solid acid catalysts, silicoaluminophosphates (SAPOs) were prepared and used in the study. Small pore $(0.4 \mathrm{~nm})$ SAPO-44 and large pore $(0.8 \mathrm{~nm})$ SAPO-5 were synthesized as per procedures reported in literature..$^{90,91}$ 


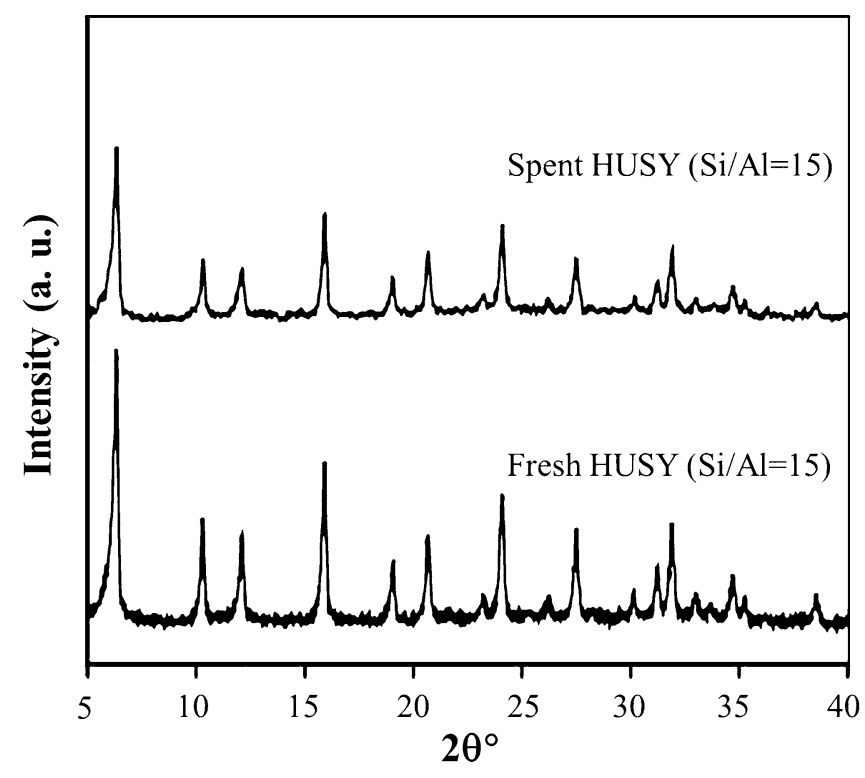

Figure 3. Comparison of XRD patterns of fresh and spent HUSY.

We have evaluated various solid acid catalysts such as $\mathrm{SiO}_{2}, \gamma-\mathrm{Al}_{2} \mathrm{O}_{3}, \mathrm{HMOR}(\mathrm{Si} / \mathrm{Al}=10)$, SAPO-5 and SAPO-44 for fructose dehydration to HMF reaction and the results are shown in figure 4. SAPO-44 was able to produce $78 \%$ of $\mathrm{HMF}$ with $88 \%$ selectivity from fructose at $175^{\circ} \mathrm{C}, 1 \mathrm{~h}$ in presence of air (1 bar) and $\mathrm{H}_{2} \mathrm{O} / \mathrm{MIBK}$ solvent system. ${ }^{93}$ A total mass balance of $94 \%$ was attained to indicate negligible carbon loss due to side reactions or else due to error in analysis. Under similar reaction condition, non-catalytic reaction gave only $29 \%$ HMF yield with $74 \%$ fructose conversion. Result was compared with HMOR catalyst as it has been shown in literature as one of the best catalysts. ${ }^{66}$

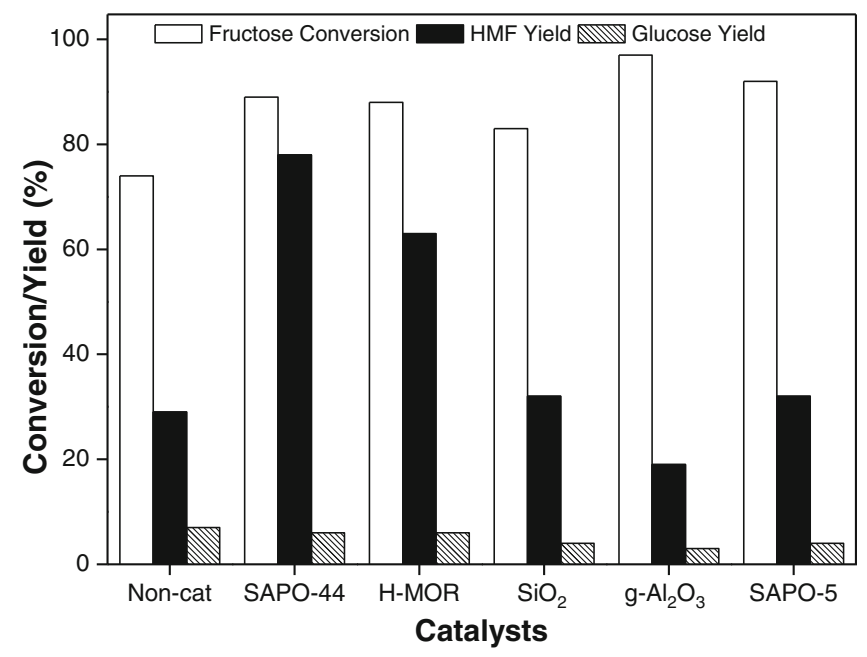

Figure 4. Conversion of fructose to HMF using solid acid catalysts. Reaction condition: fructose $(0.5 \mathrm{~g})$, catalyst $(0.143 \mathrm{~g}), \mathrm{H}_{2} \mathrm{O}+\mathrm{MIBK}=30 \mathrm{~mL}(1: 5 \mathrm{v} / \mathrm{v}), 175^{\circ} \mathrm{C}, 1 \mathrm{~h}$.
Under similar condition, HMOR catalyst showed poor performance (63\% yield, $72 \%$ selectivity), though both SAPO-44 and HMOR catalysts have same total acid amount $\left(1.2 \mathrm{mmolg}^{-1}\right)$. We also tried $\mathrm{SiO}_{2}, \gamma-\mathrm{Al}_{2} \mathrm{O}_{3}$ and SAPO- 5 catalysts but the HMF yield remains in the range of $19-32 \%$.

Various solvent systems were studied in presence of SAPO-44 catalyst to check the HMF formation. Wateronly system showed lower yield (39\%) of HMF compared to ethanol-only system (56\%). Shifting to biphasic solvent system $\mathrm{H}_{2} \mathrm{O} / \mathrm{MIBK}$, promotes $\mathrm{HMF}$ extraction from water phase to MIBK phase to improve the HMF yield (78\%). It was also observed that 1:5 ratio $(v / v)$ of $\mathrm{H}_{2} \mathrm{O} / \mathrm{MIBK}$ yields more $\mathrm{HMF}(78 \%)$ compared to that with $1: 1$ ratio (47\%); although in both cases HMF selectivity remained similar $(\sim 85 \%))^{93}$

Catalyst recycle study showed a slight decrease in activity for SAPO-44 catalyst up to 3rd run and beyond that, activity remains the same minimum up to 5 th run (66\%). Slight decrease in activity (78\% to 66\%) can be attributed to trivial structural modification in catalyst due to re-positioning of $\mathrm{Al}, \mathrm{P}$ and $\mathrm{Si}$ atoms in the framework. This data also coincided well with various physico-chemical characterizations such as XRD, ICPOES, solid state NMR and SEM images of fresh and spent catalyst. ${ }^{93}$

XRD pattern for SAPO-44 and SAPO-5 resembles CHA and AFI topology, respectively, whereas that of spent SAPO-44 showed slight change in peak intensity (figure 5). This can be compared with decrease in HMF yield in recycle runs. Now, it is essential to check whether $\mathrm{Al}$ and/or $\mathrm{P}$ were leached out during the reaction which is responsible for change in activity. To confirm this, ICP-OES analysis of fresh and spent SAPO44 was carried out and analysis indicates that amount

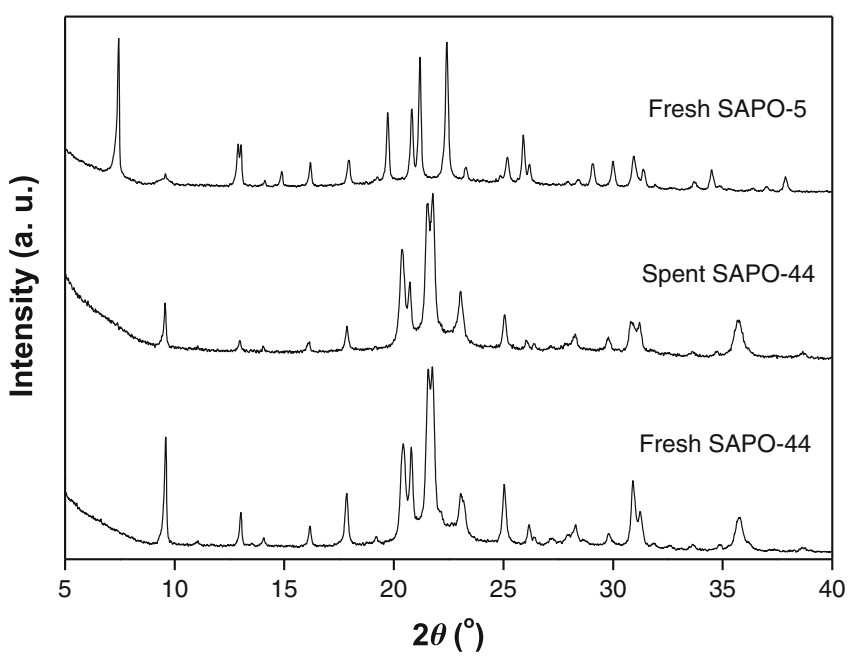

Figure 5. XRD patterns of SAPO catalysts. 


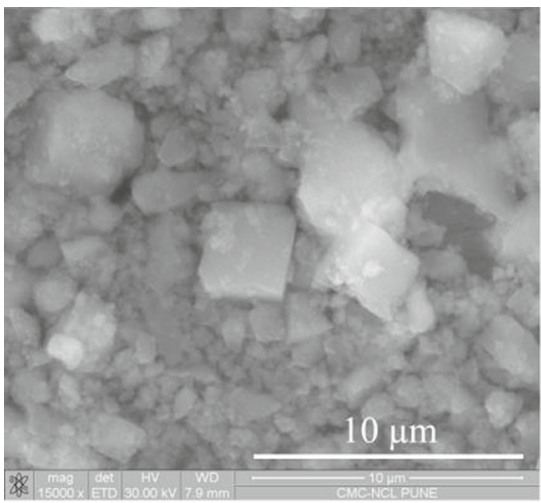

(a)

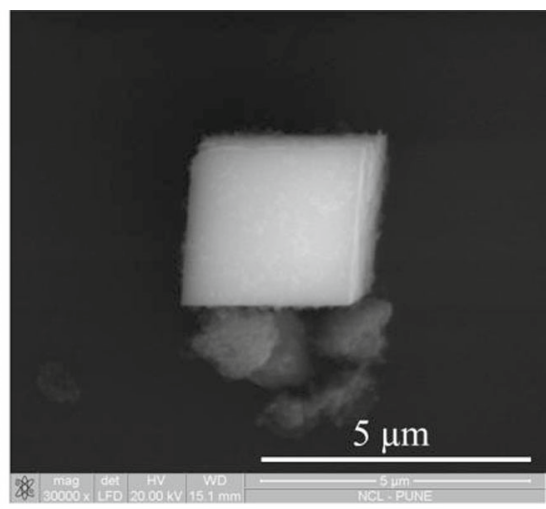

(b)

Figure 6. SEM images of SAPO-44; (a) fresh and (b) spent.

of $\mathrm{Al}$ and $\mathrm{P}$ remains same in both, fresh and spent catalysts. This indicates that in case of SAPO-44 catalyst, morphological changes are due to the repositioning of $\mathrm{Al}$ and $\mathrm{P}$. The SEM images show cubic morphology with similar edge length for both fresh and spent SAPO-44 which indicate catalyst stability (figure 6). From all the above discussions, it can be concluded that the actual active phase in the catalyst is the CHA morphology.

The catalyst in this study was used in order to introduce a more stable catalytic system compared to earlier known catalysts. However, we experienced a slight change in the morphology of SAPO during the reaction, even though it is a hydrothermally stable catalyst $\left(600^{\circ} \mathrm{C}\right.$ under $20 \%$ steam $)$. Another reason behind using SAPO catalyst was its expected superior hydrophilicity rather than zeolites due to presence of ' $\mathrm{P}$ ' in its structure. Hydrophilicity of SAPO catalyst allows it to be present in water phase where actual dehydration reaction takes place and it does not interact with extracted HMF in organic phase (condensation or degradation reaction).

\subsection{Lignin valorization}

Problems associated with known methods encourage researchers to develop a discrete method based on heterogeneous catalysts to convert real lignin substrates into aromatic monomers. Hence, the objective of our study was to develop a method to depolymerize lignin into aromatic monomer units using solid acid catalysts.

Depending on the source of plant species and also the method of extraction, the structure of lignin will differ. So before performing the reactions, lignin was well-characterized using various techniques. It was observed from MALDI-TOF analysis that dealkaline lignin had high molecular weight $(60 \mathrm{kDa})$. Since this lignin was isolated by Kraft process, both ICP-OES and EDAX analyses showed that Na contamination (29 mg $\mathrm{Na} / 1 \mathrm{~g}$ lignin) and CHNS elemental analysis showed the presence of sulphur. The CHNS elemental analysis also showed that the lignin is composed of $65 \% \mathrm{C}$ and $7 \% \mathrm{H}$. TGA analysis showed presence of $17 \%$ ignition residue in dealkaline lignin under air atmosphere and $30-40 \%$ residue under $\mathrm{N}_{2}$ atmosphere.

Lignin depolymerization was done using various solid acid catalysts such as HUSY ( $\mathrm{Si} / \mathrm{Al}=15)$, HZSM$5(\mathrm{Si} / \mathrm{Al}=11.5), \mathrm{HMOR}(\mathrm{Si} / \mathrm{Al}=10), \mathrm{K} 10$ clay and $\mathrm{SiO}_{2}-\mathrm{Al}_{2} \mathrm{O}_{3}$. Under inert atmosphere, we observed conversion of lignin to value-added aromatics with high yield of $60 \%$ and ca. $95 \%$ mass balance. Figure 7 summarizes the catalytic results obtained over various solid acid catalysts. Under the same conditions in the absence of catalyst, aromatic monomer yield was only $11 \%$, while zeolites (HUSY, HZSM-5) gave the highest

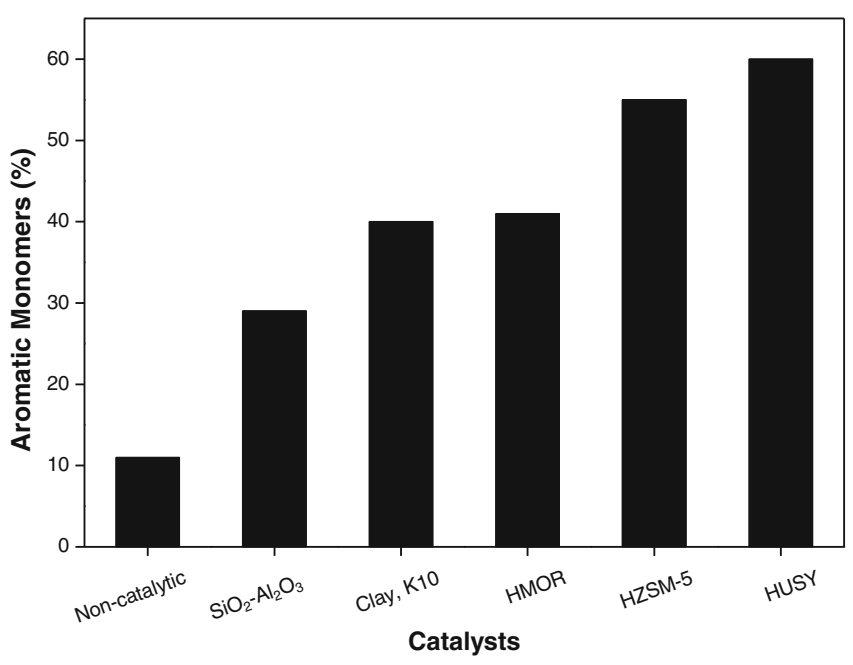

Figure 7. Study on lignin depolymerization over various solid acid catalysts. Reaction conditions: Dealkaline lignin $(0.5 \mathrm{~g})$, solid acid catalyst $(0.5 \mathrm{~g}), \mathrm{H}_{2} \mathrm{O}+\mathrm{CH}_{3} \mathrm{OH}=30 \mathrm{~mL}$ $(1: 5 \mathrm{v} / \mathrm{v}), 250^{\circ} \mathrm{C}, 0.5 \mathrm{~h}, 7$ bar $\mathrm{N}_{2}$ at RT. 
yield of ca. $60 \%$ for organic solvent soluble (THF soluble) products. Most of the other catalysts gave aromatic monomers yield of 30-40\%. ${ }^{94}$

Formation of char/tar or gas $\left(\mathrm{CO}, \mathrm{CO}_{2}, \mathrm{CH}_{4}\right.$, $\mathrm{H}_{2}, \mathrm{C}_{2}-\mathrm{C}_{4}$ ) was not observed under the reaction conditions employed. Also, the products formed in all the reactions were similar. These observations indicate that lignin depolymerization under these reaction conditions is selective in the formation of aromatic monomers. Even though zeolites showed very high activity, those were unstable under the reaction conditions. $\mathrm{XRD}, \mathrm{NH}_{3}-\mathrm{TPD},{ }^{29} \mathrm{Si}$ and ${ }^{27} \mathrm{Al}$ NMR of these catalysts revealed that its well-defined porous channel structure has collapsed. Hence, $\mathrm{SiO}_{2}-\mathrm{Al}_{2} \mathrm{O}_{3}$, a non-structured (amorphous) catalyst was used for further studies. Reaction parameters such as the temperature and pressure were studied. It revealed that $250^{\circ} \mathrm{C}$ is the optimum temperature for the formation of aromatic monomers (29\%), since further increase in temperature $\left(270^{\circ} \mathrm{C}\right)$ yields char and at lower temperatures $\left(230^{\circ} \mathrm{C}\right)$ yield of aromatic monomers was slightly decreased (25\%). Effect of pressure was also studied by charging the reactor with different pressures of $\mathrm{N}_{2}$ gas ( 1 bar and 7 bar $\mathrm{N}_{2}$ at RT) for the reaction. It was observed that 7 bar $\mathrm{N}_{2}$ pressure was the optimum pressure (29\%) for the reaction, while 1 bar $\mathrm{N}_{2}$ pressure reduced product formation (20\%). This study reveals that lignin depolymerization using solid acid catalysts is dependent on both temperature and pressure.

\subsection{Metal-exchange studies}

Recycle study of unpurified hemicellulose from bagasse showed decrease in activity of zeolite catalyst, which can be attributed to the catalyst morphology change during the reaction. ${ }^{48}$ As mentioned earlier (section 3.1), presence of $\mathrm{Na}$ and $\mathrm{K}$ was seen from the ICP-OES studies of spent catalyst. This change can be explained on the basis of metal ions present in the raw biomass which might have exchanged with Brönsted acid sites, leading to deactivation of catalyst (scheme 5). To investigate further, we carried out $\mathrm{Na}$ and $\mathrm{K}$ metal-exchange study on zeolites [HUSY ( $\mathrm{Si} / \mathrm{Al}=15), \mathrm{HMOR}(\mathrm{Si} / \mathrm{Al}=$ 10)] and silica-alumina $(\mathrm{SA}, \mathrm{Si} / \mathrm{Al}=5.8)$. All the fresh and metal-exchanged catalysts were characterized with XRD, ICP-OES and $\mathrm{NH}_{3}$-TPD.

XRD patterns of all the fresh and metal-exchanged catalysts showed no detectable change in the peak positions, which emphasizes the fact that after the metal exchange treatment, morphology of the zeolites is retained (figure 8a, b). ICP-OES and $\mathrm{NH}_{3}-\mathrm{TPD}$ data for fresh and metal-exchanged catalysts is presented in table 2. Presence of $\mathrm{Na}$ and $\mathrm{K}$ is clearly seen on the catalyst after the metal exchange treatment. This might lead to decrease in the acid amount for treated catalysts. The $\mathrm{NH}_{3}$-TPD study revealed that in case of HUSY catalysts, acid amount decreased to 0.59 and $0.56 \mathrm{mmolg}^{-1}$ after 20 and $240 \mathrm{ppm}$ treatment. Also, it is observed that the exchange tendency of $\mathrm{K}$ ion in catalyst is more pronounced than $\mathrm{Na}$ ion. From this study, it can be claimed that the presence of metal ions in raw biomass has an effect on catalyst activity reduction. However, we wish to point out here that even with 240 ppm treatment, not much decrease in the acidity compared to 20 ppm treatment, was observed (table 2). This gives us a rough idea about the presence of equilibrium between the adsorption of metal on zeolite and presence of metal in the solution. However, to prove this hypothesis, more elaborate studies are ongoing in our laboratory.

Development of a process based on biomass feedstock is advantageous and environment-friendly as discussed. However, at the same time, lignocellulosic biomass is a very complicated substrate since the composition of cellulose, hemicellulose and lignin together make it more complex and presence of nutrients (metals) in biomass kills the catalytically active sites and disrupts the catalytic process. One of the approaches to convert components of lignocellulosic biomass is to first pretreat the lignocellulose to isolate cellulose, hemicellulose and lignin and then develop individual process for them to synthesize value-added chemicals. However, pretreatment of lignocellulose has some disadvantages such as it can contaminate the substrates with additional minerals ( $\mathrm{Na}$; Kraft process), incurs extra cost and produces waste. Considering all this, it is essential that future research delves on these facts

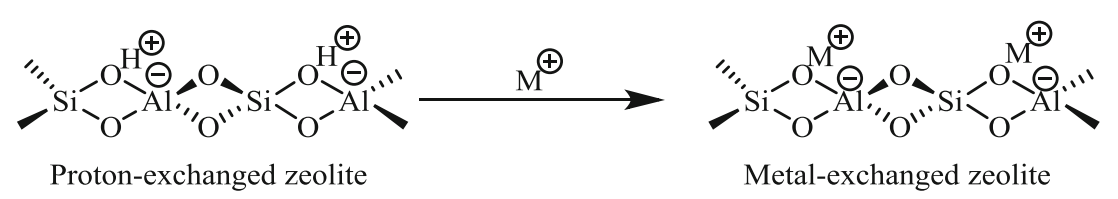

Scheme 5. Metal exchanged on protonated zeolite. 


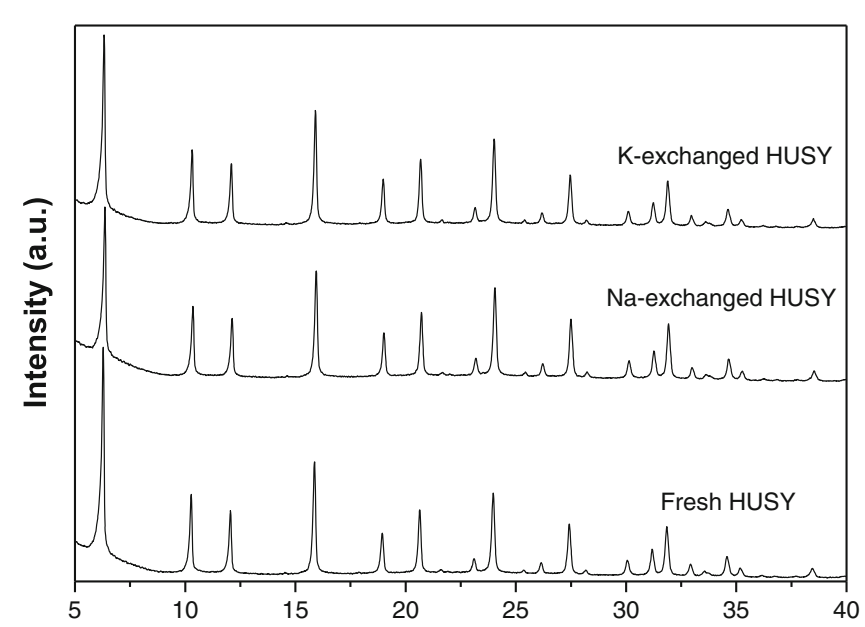

(a)

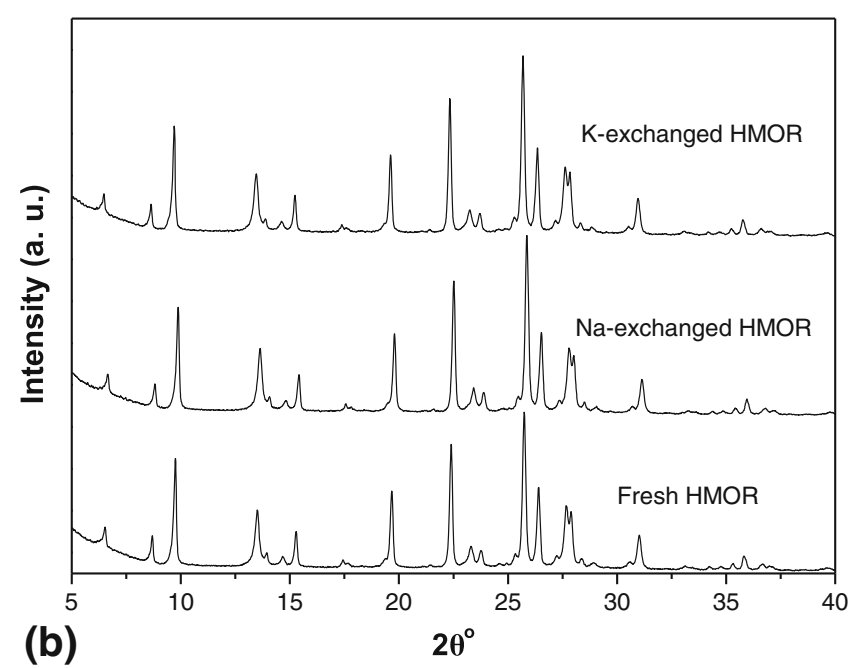

Figure 8. (a). Comparison of XRD patterns of HUSY. (b). Comparison of XRD patterns of HMOR. and devotes efforts towards developing a stable catalytic system which can convert individual parts (isolated) of lignocelluloses selectively. Another approach is that the whole lignocellulosic materials can be used as a substrate for step-by-step conversion of each components by virtue of developing multifunctional catalysts which are stable under reaction conditions. Thus, drawbacks associated with the isolation procedure can be overcome. However, development of these catalysts and fine tuning the reaction conditions is a major challenge. Hence, it is essential to work on both the approaches and try to develop efficient methods for the conversion of components of lignocellulosic biomass.

\section{Conclusion}

In summary, literature available on the use of solid acid catalysts for the formation of $\mathrm{C}_{5}$ sugars (xylose, arabinose), furan derivatives (furfural and HMF) and aromatic monomers from biomass (hemicellulose, fructose, and lignin) has been discussed here. In our study it is shown that ratio of sugars to furfural yield can be controlled by employing a specified solvent system. Recycle runs proved that zeolite catalyst was stable when pure (isolated) hemicellulose was subjected to furfural production; whereas use of bagasse (unpurified hemicellulose) did not render zeolite stability. The metal-exchange study partially explained deactivation of zeolite catalyst. To overcome the problems of zeolite catalysts, employment of SAPO catalysts because of their higher hydrothermal stability is discussed. SAPO-44 catalyst showed very high activity

Table 2. Summary on the metal-exchange study and $\mathrm{NH}_{3}-\mathrm{TPD}$ analysis of catalyst.

\begin{tabular}{lcc}
\hline Catalyst & $\mathrm{Na} / \mathrm{K}$ metal detected $(\mathrm{ppm})^{\#}$ & Total acid amount $\left(\mathrm{mmolg}^{-1}\right)^{*}$ \\
\hline Fresh HUSY & $0.26 / 0.02$ & 0.69 \\
20 ppm Na exchanged HUSY & 2.04 & 0.59 \\
240 ppm Na exchanged HUSY & 3.64 & 0.56 \\
20 ppm K exchanged HUSY & 2.08 & 0.64 \\
240 ppm K exchanged HUSY & 6.08 & 0.52 \\
Fresh HMOR & $0.17 / 0.21$ & 1.20 \\
20 ppm Na exchanged HMOR & 1.06 & 1.10 \\
240 ppm Na exchanged HMOR & 1.92 & 1.10 \\
20 ppm K exchanged HMOR & 1.87 & 1.10 \\
240 ppm K exchanged HMOR & 5.36 & 0.90 \\
Fresh SA & $2.26 / 0.17$ & 0.66 \\
20 ppm Na exchanged SA & 3.16 & 0.62 \\
240 ppm Na exchanged SA & 5.25 & 0.52 \\
20 ppm K exchanged SA & 2.29 & 0.30 \\
240 ppm K exchanged SA & 9.37 & 0.47 \\
\hline
\end{tabular}

\# ICP-OES analysis; * $\mathrm{NH}_{3}$-TPD study 
and selectivity for HMF formation from fructose. Even though a slight change in the morphology of SAPO-44 was observed in spent catalyst after 1st run, it can show similar activity after 3 rd recycle run onwards. Valorization of lignin to aromatic monomers with high yield was also described with zeolite catalyst but its stability is an issue. This problem can be overcome by using amorphous catalysts.

\section{References}

1. Cao Q, Guo X, Guan J, Mu X and Zhang D 2011 Appl. Catal. A: Gen. $\mathbf{4 0 3} 98$

2. Alonso D M, Bond J Q and Dumesic J A 2010 Green Chem. 121493

3. Geboers J A, Van de Vyver S, Ooms R, Op de Beeck B, Jacobs P A and Sels B F 2011 Catal. Sci. Technol. 1714

4. Kobayashi H, Ohta H and Fukuoka A 2012 Catal. Sci. Technol. 2869

5. Rosatella A A, Simeonov S P, Frade R F M and Afonso C A M 2011 Green Chem. 13754

6. Binder J B and Raines R T 2009 J. Am. Chem. Soc. 131 1979

7. Fan L T, Gharpuray M M and Lee Y H 1987 Cellulose hydrolysis (Heidelberg, Berlin: Springer-Verlag) vol. 3, p. 1-68.

8. Pandey A, Biswas S, Sukumaran R and Kausik N 2009 Availability of Indian Biomass Resources for Exploitation (ed) Chidamabaram R, Technology Information Forecasting \& Assessment Council

9. Drummond A R F and Drummond I W 1996 Ind. Eng. Chem. Res. 351263

10. James O O, Maity S, Usman L A, Ajanaku K O, Ajani O O, Siyanbola T O, Sahu S and Chaubey R 2010 Energ. Environ. Sci. 31833

11. Karinen R, Vilonen K and Niemela M 2011 Chem. Sus. Chem. 41002

12. Serrano Ruiz J C, Luque R and Sepulveda Escribano A 2011 Chem. Soc. Rev. 405266

13. Stark K, Taccardi N, Bosmann A and Wasserscheid P 2010 Chem. Sus. Chem. 3719

14. Hu L, Zhao G, Hao W, Tang X, Sun Y, Lin L and Liu S 2012 RSC Adv. 211184

15. Sitthisa S and Resasco D 2011 Catal. Lett. 141784

16. West R M, Liu Z Y, Peter M, Gartner C A and Dumesic J A 2008 J. Mol. Catal. A: Chem. 29618

17. Kim M G, Boyd G and Strickland R 1994 Holzforschung 486

18. Weingarten R, Cho J, Conner J W C and Huber G W 2010 Green Chem. 121423

19. Riansa Ngawong W and Prasertsan P 2011 Carbohydr. Res. 346103

20. Yemis O and Mazza G 2011 Bioresour. Technol. 102 7371

21. O'Neill R, Ahmad M N, Vanoye L and Aiouache F 2009 Ind. Eng. Chem. Res. 484300

22. Choudhary V, Pinar A B, Sandler S I, Vlachos D G and Lobo R F 2011 ACS Catal. 11724

23. Lam E, Chong J H, Majid E, Liu Y, Hrapovic S, Leung A C W and Luong J H T 2012 Carbon 501033
24. Karinen R, Vilonen K and Niemela M 2011 Chem. Sus. Chem. 41002

25. Takagaki A, Ohara M, Nishimura S and Ebitani K 2010 Chem. Lett. 39838

26. Lam E, Majid E, Leung A C W, Chong J H, Mahmoud K A and Luong J H T 2011 Chem. Sus. Chem. 4535

27. Dias A S, Pillinger M and Valente A A 2005 J. Catal. 229414

28. Kim S, You S, Kim Y, Lee S, Lee H, Park K and Park E 2011 Kor. J. Chem. Eng. 28710

29. Dias A S, Lima S R, Pillinger M and Valente A A 341 Carbohydr. Res. 2946.

30. Dias A S, Pillinger M and Valente A A 2006 Micro. Meso. Mater. 94214

31. Daengprasert W, Boonnoun P, Laosiripojana N, Goto M and Shotipruk A 2011 Ind. Eng. Chem. Res. 507903

32. Zhang J, Zhuang J, Lin L, Liu S and Zhang Z 2012 Biomass Bioenerg. 3973

33. Moreau C, Durand R, Peyron D, Duhamet J and Rivalier P 1998 Ind. Crop. Prod. 795

34. Croker J R and Bowrey R G 1984 Ind. Eng. Chem. Fund. 23480

35. Lessard J, Morin J F, Wehrung J F, Magnin D and Chornet E 2010 Top. Catal. 531231

36. Antunes M M, Lima S, Fernandes A, Pillinger M, Ribeiro M F and Valente A A 2012 Appl. Catal. A: Gen. 243 417-418.

37. Lima S R, Pillinger M and Valente A A 2008 Catal. Commun. 92144

38. Shi X, Wu Y, Li P, Yi H, Yang M and Wang G 2011 Carbohydr. Res. 346480

39. Suzuki T, Yokoi T, Otomo R, Kondo J N and Tatsumi T 2011 Appl. Catal. A: Gen. 408117

40. Sadaba I, Lima S R, Valente A A and Lopez Granados M 2011 Carbohydr. Res. 3462785

41. Shi X, Wu Y, Yi H, Rui G, Li P, Yang M and Wang G 2011 Energies 4669

42. Agirrezabal Telleria I, Larreategui A, Requies J, Guemez M B and Arias P L 2011 Bioresour. Technol. 102 7478

43. Lima S R, Fernandes A, Antunes M, Pillinger M, Ribeiro F and Valente A 2010 Catal. Lett. 13541

44. Dias A S, Lima S R, Carriazo D, Rives V, Pillinger M and Valente A A 2006 J. Catal. 244230

45. Tao F, Song H and Chou L 2011 Can. J. Chem. 8983

46. Lima S R, Neves P, Antunes M M, Pillinger M, Ignatyev N and Valente A A 2009 Appl. Catal. A: Gen. 36393

47. Dhepe P L and Sahu R 2010 Green Chem. 12153

48. Sahu R and Dhepe P L 2012 Chem. Sus. Chem. 5751

49. Kim Y, Hendrickson R, Mosier N and Ladisch M R 2005 Energ. Fuel 192189

50. Kim S B and Lee Y Y 1985 Biotechnol. Bioeng. Symp. 1583

51. Kusema B T, Hilmann G, Maki Arvela P, Willfor S, Holmbom B, Salmi T and Murzin D 2011 Catal. Lett. 141408

52. Bicker M, Hirth J and Vogel H 2003 Green Chem. 5280

53. Zakrzewska M E, Bogel-Lukasik E and Bogel Lukasik R 2011 Chem. Rev. 111397

54. Leshkov Y R, Barrett C J, Liu Z Y and Dumesic J A 2007 Nature 447982

55. Yang W and Sen A 2010 Chem. Sus. Chem. 3597 
56. Xiang X, He L, Yang Y, Guo B, Tong D and Hu C 2011 Catal. Lett. 141735

57. Gupta N K, Nishimura S, Takagaki A and Ebitani K 2011 Green Chem. 13824

58. Peng L, Lin L, Zhang J, Zhuang J, Zhang B and Gong Y 2010 Molecule 155258

59. Huber G W, Chheda J N, Barrett C J and Dumesic J A 2005 Science 3081446

60. Qi X, Watanabe M, Aida T M and Smith R L 2008 Catal. Commun. 92244

61. Dutta S, De S, Patra A K, Sasidharan M, Bhaumik A and Saha B 2011 Appl. Catal. A: Gen. 133 409-410

62. Shimizu K, Uozumi R and Satsuma A 2009 Catal. Commun. 101849

63. Takagaki A, Ohara M, Nishimura S and Ebitani K 2009 Chem. Commun. 6276

64. Zhu H, Cao Q, Li C and Mu X 346 Carbohydr. Res. 2016.

65. Lai L and Zhang Y 2011 Chem. Sus. Chem. 41745

66. Moreau C, Durand R, Razigade S, Duhamet J, Faugeras P, Rivalier P, Ros P and Avignon G 1996 Appl. Catal. A: Gen. 145211

67. Ordomsky V V, van der Schaaf J, Schouten J C and Nijhuis T A 2012 J. Catal. 28768

68. Zhao Q, Wang L, Zhao S, Wang X and Wang S 2011 Fuel 902289

69. Fan C, Guan H, Zhang H, Wang J, Wang S and Wang X 2011 Biomass Bioenerg. 352659

70. Yang F, Liu Q, Yue M, Bai X and Du Y 2011 Chem. Commun. 474469

71. Qi X, Watanabe M, Aida T M and Smith R L 2008 Ind. Eng. Chem. Res. 479234

72. Moliner M, Roman Leshkov Y and Davis M E 2010 Proc Natl. Acad. Sci. 1076164

73. Nikolla E, Roman Leshkov Y, Moliner M and Davis M E 2011 ACS Catal. 1408
74. Yamaguchi K, Sakurada T, Ogasawara Y and Mizuno N 2011 Chem. Lett. 40542

75. NREL/BR-510-40742 March 2007 Research Advances Cellulosic Ethanol, NREL Leads the Way

76. Shabtai J S, Zmierczak W W and Chornet E 1999 U.S. Patent 595916

77. Shabtai J S, Zmierczak W W and Chornet E 2001 U.S. Patent 6172272

78. Watanabe M, Inomata H, Osada M, Sato T, Adschiri T and Arai K 2003 Fuel 82545

79. Roberts V M, Stein V, Reiner T, Lemonidou A, Li X and Lercher J A 2011 Chem. Eur. J. 175939

80. Harris E E, D'Ianni J and Adkins H 1938 J. Am. Chem. Soc. 601467

81. Pepper J M and Lee Y W 1969 Can. J. Chem. 47723

82. Thring R W and Breau J 1996 Fuel 75795

83. Ratcliff M A, Johnson D K, Posey F L and Chum H L 1988 Appl. Biochem. Biotechnol. 17151

84. Meier D, Ante R and Faix O 1992 Bioresour. Technol. 40171

85. Adjaye J D and Bakhshi N N 1995 Fuel Process. Technol. 45161

86. Wahyudiono Kanetake T, Sasaki M and Goto M 2007 Chem. Eng. Technol. 301113

87. Wahyudiono Sasaki M and Goto M 2009 Fuel 881656

88. Sharma R K and Bakhshi N N 1991 Bioresour. Technol. 3557

89. Misson M, Haron R, Kamaroddin M F A and Amin N A S 2009 Bioresour. Technol. 1002867

90. Prakash A M, Unnikrishnan S and Rao K V 1994 Appl. Catal. A: Gen. 1101

91. Sinha A K, Sainkar S and Sivasanker S 1999 Micropor. Mesopor. Mater. 31321

92. Bandura A V and Lvov S N 2006 J. Phys. Chem. Ref. Data 3515

93. Bhaumik P and Dhepe P L 2013 RSC Adv. 317156

94. Deepa A K and Dhepe P L 2014 RSC Adv. 412625 